\title{
Key actors' involvement in implementing assessment reforms and using quality improvement measures
}

\author{
Guri Skedsmo $^{1,2} \cdot$ Stephan Gerhard Huber $^{1}$
}

Published online: 2 June 2018

(C) Springer Science+Business Media, LLC, part of Springer Nature 2018

In recent years, education reforms in many countries have focused on elements such as competences, performance standards and technologies to measure educational quality, producing data for use in decision-making and quality improvement at all levels of the school system (Lingard et al. 2013). As part of this trend, key actors, including school leaders and teachers, are expected to be more open and responsive to external judgments of their work and outcomes (Prøitz et al. 2017; Sun et al. 2016). In terms of local policy implementation, the autonomy of teachers and school leaders depends on the prevailing system of governance and the logics of accountability that inform performance management. Drawing on concepts originally developed by Sears and Marshall (1990) in the context of local curriculum work, these implementation processes can be said to take one of two general forms: 'empowerment-as-authorisation' or 'empowerment-as-enablement'. While the former is a top-down process in which teachers and school leaders implement decisions from above, the latter gives them more leeway to adapt policy to the local context on the basis of their professional knowledge and capabilities. Most often, implementation processes are likely to include both forms of empowerment. All of the articles in this issue of EAEA address reform implementation, quality improvement and key actors' involvement in such activities which can be seen through the lens of empowerment.

Guri Skedsmo

guri.skedsmo@ils.uio.no

Stephan Gerhard Huber

stephan.huber@phzg.ch

1 Institute for the Management and Economics of Education, University of Teacher Education Zug, Zug, Switzerland

2 Department of Teacher Education and School Research, University of Oslo, Oslo, Norway 


\section{Articles in this issue of EAEA 2/2018}

In the first article, Murchan investigates Ireland's Framework for Junior Cycle, which introduces school-based assessment for lower-secondary education. Analysing the process of national adaptation as well as international influences on how this reform was conceptualised, he identifies several 'push' factors from within the Irish education system and a number of external 'pull' factors that reflect elements of policy borrowing. Murchan notes that teachers' critical voices prompted adjustments to policy proposals, leading to the retention of certain pre-reform arrangements. In general, the paper illustrates the difficulty of introducing policies and practices that have succeeded elsewhere unless legitimised by teachers' support and the involvement of key actors in reform implementation.

In the second article, Young, McNamara, Brown and O'Hara's analysis examines school leaders' use of data in seven Irish schools following the introduction of mandatory school self-evaluation in 2011 based on new practices for data use. Interviews with school leaders reveal that schools use data from standardised testing, student attendance and student profiling (e.g. special educational needs). In line with research from other countries, they note the crucial role of principals in driving data utilisation and developing data use practices, given the lack of policy, structures and support at both local and national levels. Their finding that teachers have so far had little involvement in data analysis and decision-making processes indicates that current data use practices are largely seen as a management function. The authors discuss possible consequences for school organisation if data use became more of a joint enterprise.

In the third article, Gaertner and Brunner asked students in Germany (Berlin and Brandenburg) to evaluate the quality of teaching they received. The authors argue that the use of feedback data for evaluating teachers and making decisions about the development of teaching practices depends on showing that such measures are sufficiently stable to be generalised to other teaching situations. To that end, they investigated the moderating influence of three situational factors: time between assessments, subjects taught by teachers and students' grade levels. Of 16 teaching constructs they examined, 12 were affected only slightly by these three factors. Interestingly, only four constructs (including students' perceptions of the student-teacher relationship and classroom management) seemed to vary across time, subject and grade. Based on their analysis, the authors make recommendations for the use of student feedback data in evaluating teaching quality.

In the fourth article, Zuber and Altrichter's perspective on reform and change processes in schools is more person-oriented. Based on a survey of school leaders in one Austrian state, they investigate the extent to which individual characteristics are predictive of teachers' behaviour in a context where competence-based performance standards and nation-wide comparative performance tests have been introduced during the last decade. These reforms impose clearer performance expectations on all actors in the school system, with an increased focus on improving students' basic skills. This requires teachers to develop a more competence-oriented teaching style and to use student achievement data to inform and improve their teaching practice. The authors conclude that teachers who have a positive self-concept and high levels of positive affectivity are more likely to exhibit a positive attitude to such reforms, along with appropriate changes in teaching behaviour. 


\section{Reflections on the contributions}

Murchan shows how policy implementation in Ireland was strongly influenced by borrowing policies legitimised by their success in other contexts. The article also describes a process of attraction before ideas were concretised and decisions encapsulated in the 2012 Framework for Junior Cycle. In particular, Murchan shows that certain elements proved difficult to implement because a strong teaching profession was empowered to oppose reform.

Young et al. report how school leaders in seven Irish schools were empowered to develop data practices to analyse school results as a basis for making improvement decisions. The use of evaluation tools and methods to identify priorities suggests directions for further work.

Based on their finding that 12 of 16 constructs tested offer stable measures of teaching quality, Gaertner and Brunner encourage teachers to use such data in combination with their knowledge about the classroom context to inform and develop their own professional practice. However, they urge caution in using such data for external evaluation of teachers' work, as additional data would be needed to assess the teacher's general teaching capacity.

The article by Zuber and Altrichter attempts to link personal characteristics to the intended outcomes of a specific reform. They argue that it may be worthwhile to include such factors when studying the processes and effects of implementing performance standards and feedback. Their account of the governing context indicates a system in which reforms are implemented top-down. As compared to the Irish context described by Murchan, where teachers' resistance is depicted as a productive force in reform implementation, the Austrian case highlights teacher characteristics that predict positive behaviour during change as important for implementation. A positive disposition to change may also facilitate more general empowerment.

We have argued that implementation processes probably include both empowerment-as-authorisation and empowerment-as-enablement (cf. Sears and Marshall (1990), but which should be emphasised in which context? Is one better than the other? In many cases, the two may appear in parallel, as acting on policies involves interpretation by key actors, which may be more or less explicit. How these two forms play out will depend on cultural context, professional traditions and professional beliefs.

\section{References}

Lingard, B., Martino, W., \& Rezai-Rashti, G. (2013). Testing regimes, accountabilities and education policy: commensurate global and national developments. Journal of Education Policy, 28(5), 539-556.

Prøitz, T. S., Mausethagen, S., \& Skedsmo, G. (2017). Investigative modes in research on data use in education. Nordic Journal of Studies in Educational Policy, 3(1), 42-55. https://doi.org/10.1080 /20020317.2017.1326280.

Sears, J. T., \& Marshall, J. D. (Eds.). (1990). Teaching about curriculum: critical inquiries. New York: Teachers College Press.

Sun, J., Przybylski, R., \& Johnson, B. J. (2016). A review of research on teachers' use of student data: from the perspective of school leadership. Educational Assessment, Evaluation and Accountability, $28(1), 5-33$. 